\title{
The Canadian Journal of Infectious Diseases and The Canadian Infectious Disease Society - New beginnings, at the right time
}

$\mathrm{T}$ HE BEGINNING IS THE MOST IMPORTANT PART OF THE WORK - this famous quote from Plato over 2000 years ago remains timeless. But please read more than the beginning of this editorial.

This issue of The Canadian Journal of Infectious Diseases begins a new relationship between the Canadian Infectious Disease Society (CIDS) and the Journal. The CIDS and the publishers from Pulsus Group Inc have agreed to a contract in which the Journal is the official scientific publication of the Society. In this relationship, the Society appoints the editor who, together with the editorial board, is responsible for the scientific content of the Journal. In addition, the Society has approved the formation of a Publications Committee (similar to the other Ad Hoc Committees of the Society) to provide guidance, direction and support for the editor.

There are many advantages to the Society from such a relationship. It provides the members of the Society and other investigators with a much needed opportunity for publications in the field of original infectious diseases research in Canada. In addition, it provides a forum for education through dissemination of information from symposia and guidelines in special communications and supplements. It also facilitates an opportunity for editorial comment on important infectious diseases issues. Pulsus Group Inc has also generously agreed to publish our Society newsletter as an insert in those copies distributed to cIDs members. Finally, there is a small but tangible financial benefit to the Society. In turn, we believe that the leadership provided by the Society, together with the publications submitted by members, will continue to improve the quality and impact of the Journal.
The future should hold even brighter promise for the Journal; the frequency of publication recently has increased from four to six issues annually, distributed to over 20,000 physicians. This number will likely increase, as the publishers are intending a broader distribution outside of Canada. It also is anticipated that the number of submitted articles will increase from outside Canada. The endorsement by the Society of Canadian Journal of Infectious Diseases as the official CIDs journal will assist plans for citation indexing. This will help ensure further Canadian and international recognition and impact of the Journal.

These developments would not be possible without the enthusiasm and support of many individuals. In particular, we owe a debt of gratitude to Pulsus Group Inc and its publisher Robert Kalina for their continued support. We also thank the leadership provided for the Society by Dr Lindsay Nicolle, Editor-in-Chief, who has devoted a great deal of effort to nurture the Journal since its birth. Many current and former members of Council of the Society, as well as our Secretariat, have been involved in the discussion and review of proposals with Pulsus Group Inc. In particular, the Society acknowledges the Ad Hoc Working Committee consisting of Drs Ron Feld, Pierre Turgeon and Lil Miedzinski who have reviewed specific proposals and negotiated some of the final terms. Their efforts and those of many others have been important in encouraging this relationship.

We wish success for Pulsus Group Inc, Dr Lindsay Nicolle, her editorial staff and the publications subcommittee in the new beginnings of the relationship between the CIDS and The Canadian Journal of Infectious Diseases. 
My remaining editorial space is devoted to showing how the Journal can help in our struggle with infectious diseases. It is important for cIDs to alert its members and the broader audience of this Journal to the uncertainty of Federal funding for the acquired immune deficiency syndrome (AIDS) research in Canada. It is disturbing when the continuing financial support in the fight against an important new infectious disease such as AIDS is uncertain. Are you aware that the five-year federal funding for AIDS research expires March 31 , 1993, with no approved plans beyond that date.

We are, therefore, starting a new beginning in the fight against one of our newest and most challenging infectious diseases - AIDS - and its associated opportunistic infections. These have demonstrated very vividly once again that the microbial world can exploit human behaviour, societal inadequacies and immunological deficiency. In spite of recommendations by the Royal Society of Canada, we have no stable long term funding for AIDs research in Canada.

Why is AIDS research important? Previous AIDS research dollars have been used to fund innovative community service prevention and care, clinical trials, epidemiological studies, and basic science microbiology and immunology investigations. This research funding has also contributed to enhanced communication and training of investigators to meet these challenges.
These developments are becoming effective and must be fostered. Infectious disease physicians and other doctors who now provide care of human immunodeficiency virus-infected patients should be very concerned about the lack of continuity of future AIDS research funding. We need open discussion on this issue. Won't you help ask the right questions now, so that the leadership and answers provided by AIDS researchers will continue? Some appropriate questions to focus at the Federal level are "What will be the amount of future AIDS research funding?" and "When will the research community know about Federal Government financial commitment to AIDS research?" Please interact with interested health professionals, the public and community groups to raise this issue to greater awareness. By strengthening and sharpening the debate on AIDS research, we may help to forge a strong policy in the fight against this terrible disease.

Thank you, The Canadian Journal of Infectious Diseases, for your timely new beginnings.

GHammond, MD, FRCPC Past-President Canadian Infectious Diseases Society (CIDS) Winnipeg, Manitoba 


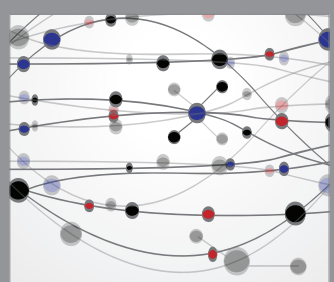

The Scientific World Journal
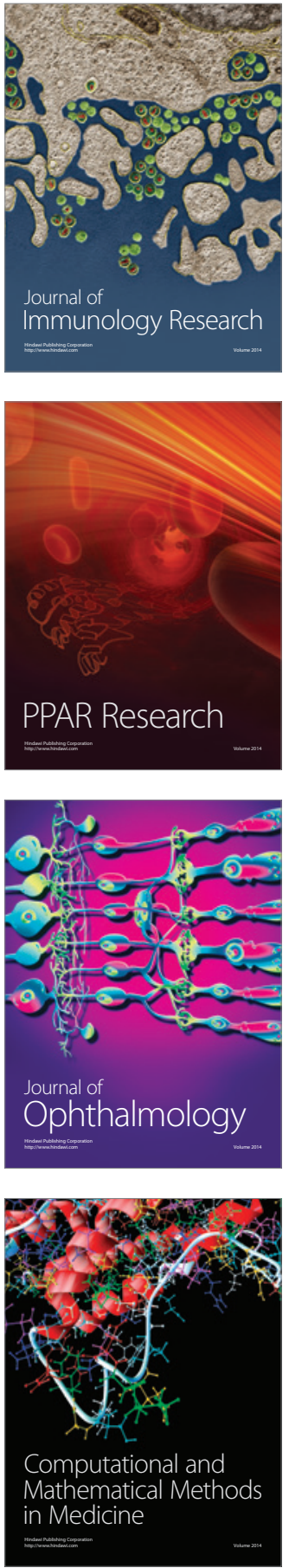

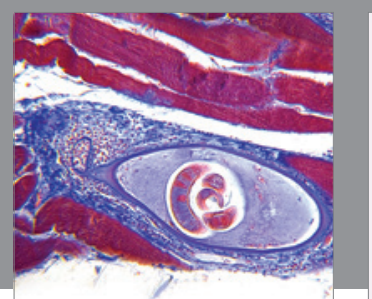

Gastroenterology Research and Practice

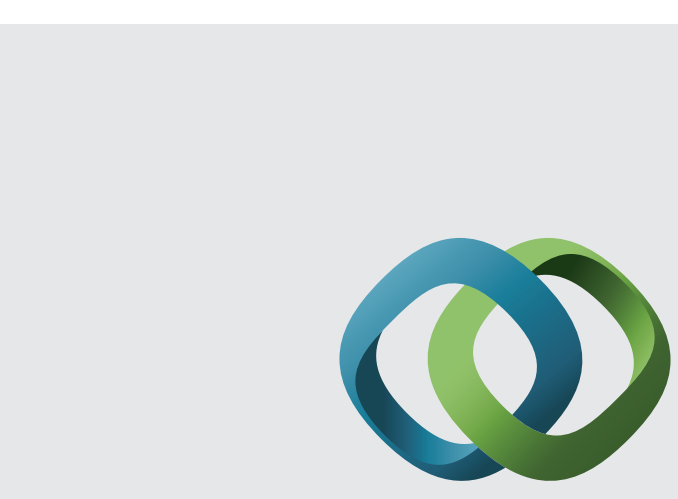

\section{Hindawi}

Submit your manuscripts at

http://www.hindawi.com
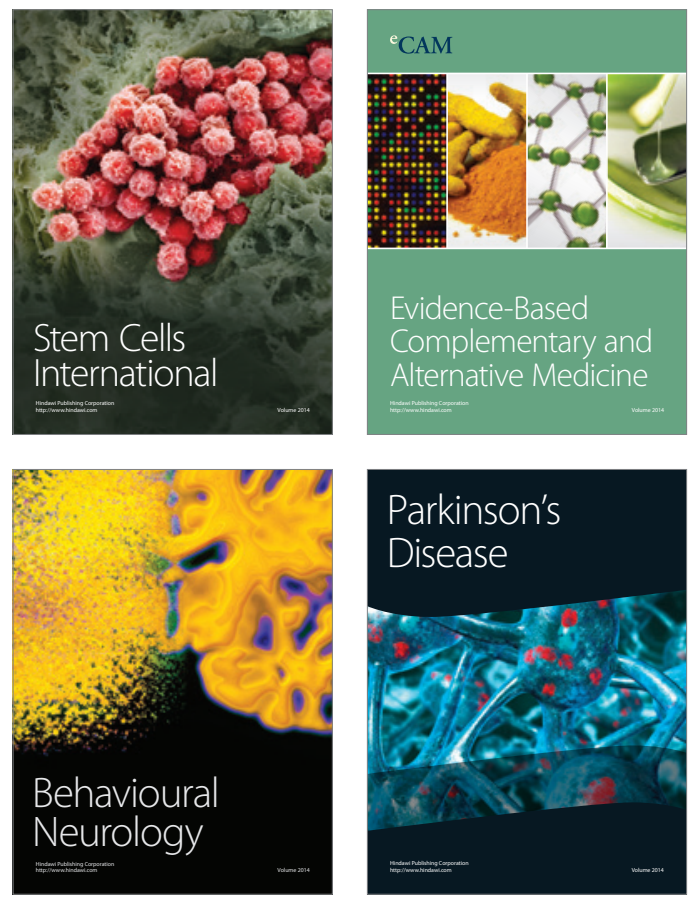
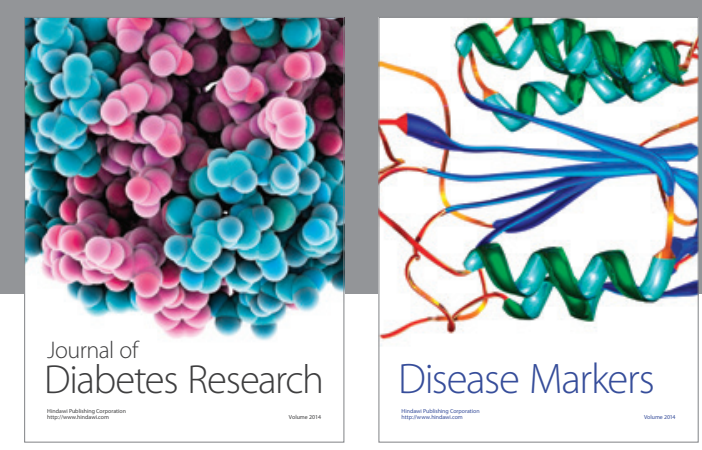

Disease Markers
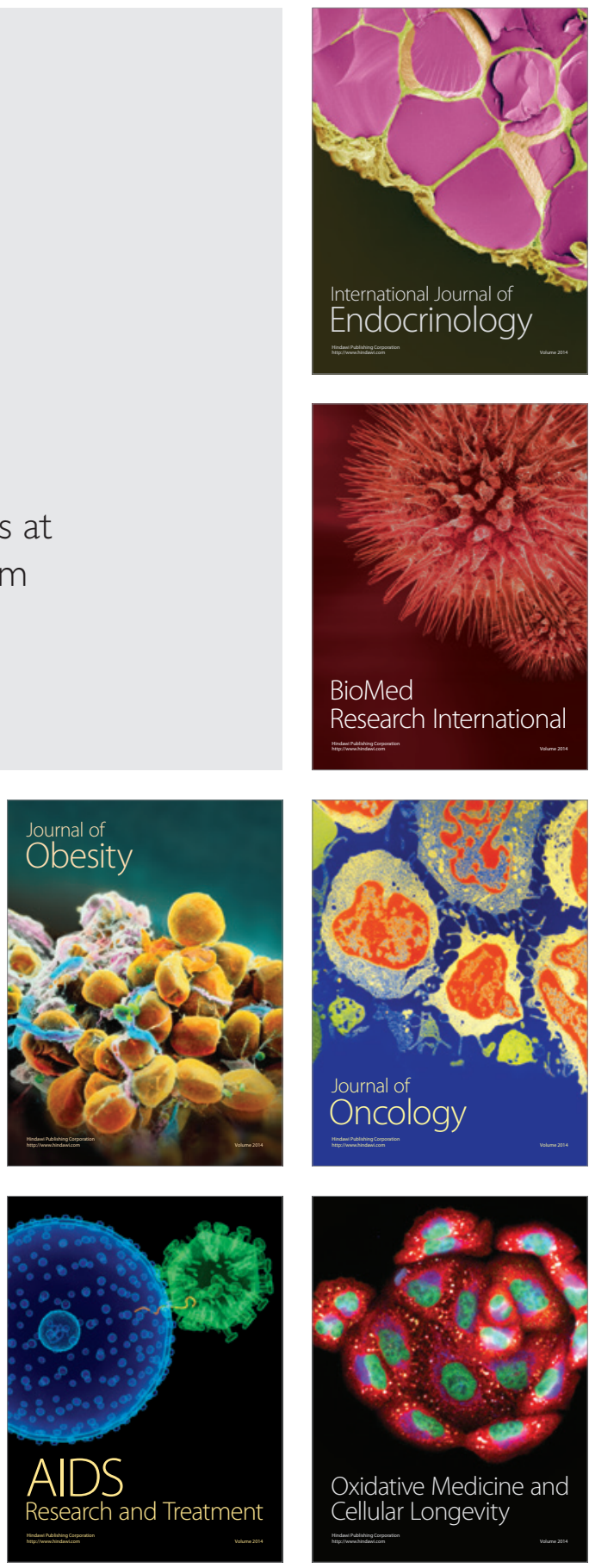